\title{
A rare case of sclerosing stromal tumor of ovary with Meigs syndrome presenting with torsion
}

\author{
Ketaki K. Junnare ${ }^{1}$, Pramod Tajne ${ }^{1}$, Pushpalata R. Naphade ${ }^{1}$ \\ ${ }^{1}$ Department of Obstetrics and Gynaecology, Smt Kashibai Navale Medical College, Pune, Maharashtra, India
}

\section{A B S T R A C T}

A young primi para presented with a large solid ovarian mass with ascites and hydrothorax. She had raised CA 125 levels. She developed torsion of the mass after admission. At laparotomy the tumor was subjected to frozen section. The tumor was benign sclerosing stromal tumor of ovary. Uterus and normal ovary could be conserved.
Access this article online

Website:

http://nepjol.info/index.php/AJMS

Key words: Sclerosing stromal tumor, Meigs syndrome, Torsion

\section{INTRODUCTION}

A solid ovarian tumor with raised CA 125 levels points towards a possibility of malignant tumor. In a young patient with such clinical scenario there is always a dilemma regarding conservation of uterus and other ovary. Sclerosing stromal tumor (SST) is benign solid ovarian neoplasm of the sex cord stromal category. It is an extremely rare tumor presenting in the second and third decades of life, and they are unilateral. ${ }^{1}$ The tumor with rare exception is hormonally inactive. All reported cases of SST have been benign. ${ }^{1}$ This is a rare presentation of SST with Meigs syndrome with elevated serum Ca125 levels.

\section{CASE REPORT}

A 24 year old primipara, presented with pain in abdomen and abdominal distention for a month. There was no history of amenorrhoea. Clinical examination revealed a large palpable abdomino-pelvic mass, ascites. She was admitted in gynaecology ward and was investigated. Her CA 125 level was $339.20 \mathrm{IU} / \mathrm{ml}$. Ultrasonography revealed a mass $15 \mathrm{~cm} \times 14 \mathrm{~cm} \times 6 \mathrm{~cm}$ arising from right ovary with solid and cystic areas. CT scan demonstrated large pelvic mass accompanied by ascites and right pleural effusion (Figure 1). X-ray chest showed 600-700 cc pleural effusion with collapse of underlying lung field (Figure 2).
On second day patient had breathlessness, fever, nausea and acute abdominal pain. Intercostal chest drain was kept after ruling out malignancy by diagnostic pleural tapping. Approximately $800 \mathrm{cc}$ haemorrhagic pleural fluid was drained. Decision of exploratory laparotomy was taken with suspicion of torsion. On laparotomy a large bosselated right ovarian tumor with torsion involving fallopian tube was noticed with gross ascitic (Figure 3). About $550 \mathrm{cc}$ ascetic fluid was drained. Ascitic fluid was sent for cytology. Left ovary, fallopian tube \& uterus were unremarkable. There was no evidence of any other mass or metastasis in the peritoneal cavity.

Right salpingo-oophorectomy was performed. Frozen sections of the tumor demonstrated benign sclerosing stromal tumor of ovary (Figure 4). Ascitic fluid was negative for malignancy. Histopathology later confirmed the diagnosis. Patient had an uneventful post-operative recovery. with spontaneous resolution of ascites and pleural effusion (Figure 5).

\section{DISCUSSION}

Sclerosing stromal cell tumor is a rare benign tumor of ovarian stroma, first described by Chalvaridjian and Scully (1973), ${ }^{2}$ SSTs occur in the second or third decades. ${ }^{1}$ The most common presentation includes menstrual irregularity, pelvic pain and non-specific symptoms related to ovarian mass. ${ }^{3}$ Our patient had pelvic mass, pain but no menstrual irregularities. In 1989, Jones and Surwit reported on patients with Meigs 

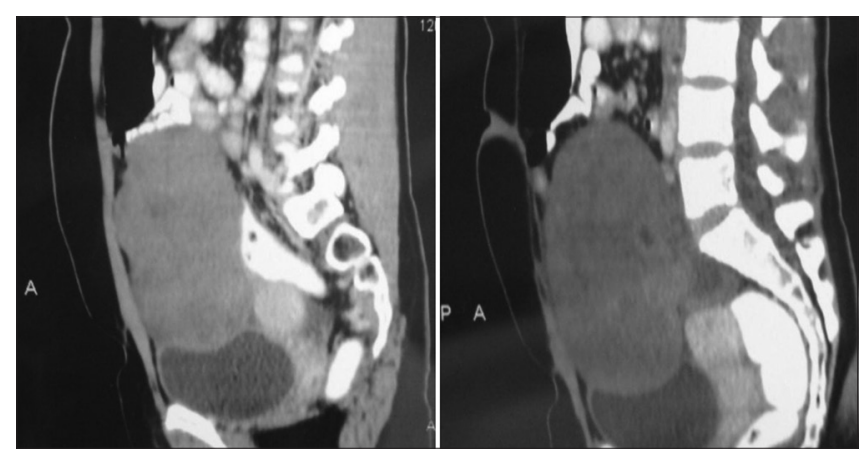

Figure 1: CT Abdomen and pelvis - Solid ovarian mass

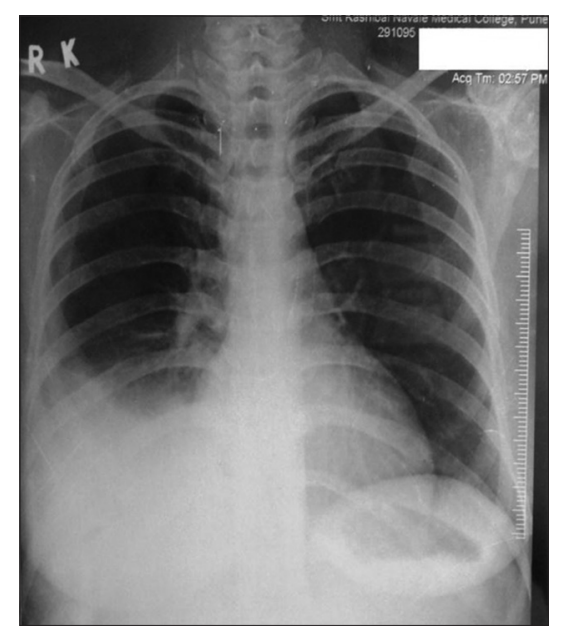

Figure 2: X ray chest - Right sided pleural effusion (pre operative)

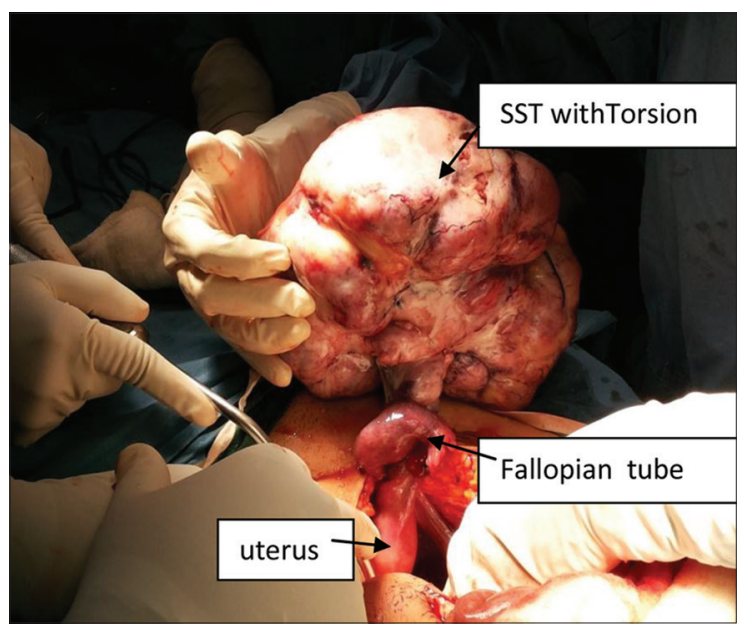

Figure 3: SST with Torsion $18 \mathrm{~cm} \times 14 \mathrm{~cm} \times 7 \mathrm{~cm}$ with bosselated external surface. Cut section was solid grayish-white \& variegated with yellowish cystic areas

syndrome associated with fibroma - thecoma of the ovary and elevated CA 125 levels. Since then 38 cases have been reported, including four with SSTs. ${ }^{2}$ We report fifth case of Meigs syndrome associated with SST of the ovary.

In our case, patient had pain, abdominal mass, ascites, pleural effusion who later developed torsion. M.V.C. de Silva et al have

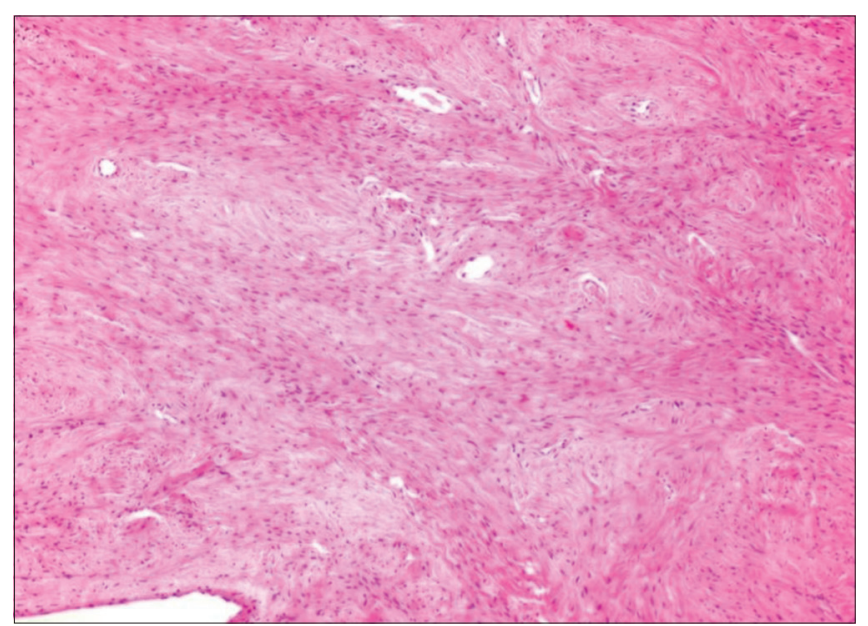

Figure 4: Hypocellular \& hypercellular areas with vagelobulation of cellular areas along with many ectatic thin walled blood vessels

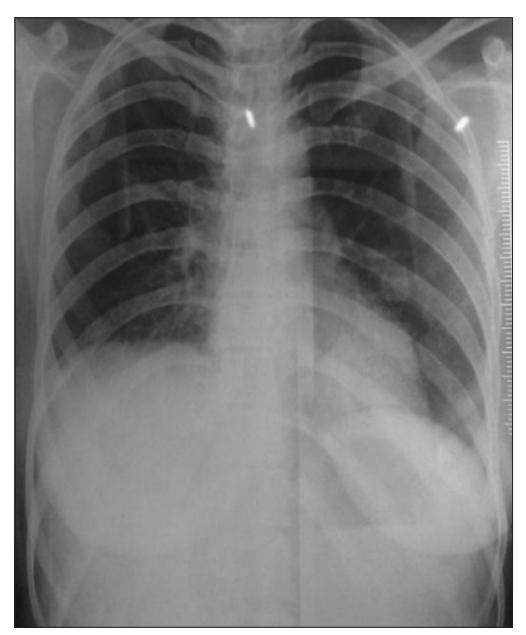

Figure 5: $\mathrm{X}$ ray chest $\mathrm{PA}$ view - One week after surgery

reported an unusual case of SST who presented as torsion. ${ }^{4}$ The mechanism by which peritoneal and pleural effusion develops is still unknown. Meigs suggested that irritation of the pleural surface or leakage from edematous ovarian stroma of the tumor could stimulate peritoneal fluid production. The other mechanism includes obstructon or congestionof peritoneal lymphatics \& veins by the tumor, increased vascular permeability or transudation by tumor surface. ${ }^{5}$

CA 125, a high molecular weight glycoprotein is now the most commonly used serum biomarker for ovarian tumors, though it has low specificity as increased level are found in so many malignancies and non-malignant condition. In Meigs syndrome, the elevation of serum CA125 levels may result from mesothelial expression of the tumor marker. A significant linear correlation between volume of pleural effusion and serum Ca125 values has been demonstrated in both benign and malignant diseases. ${ }^{2}$ Similar correlation has been demonstrated between CA125 elevation and volume of ascites in Meigs syndrome. ${ }^{2}$ Our patient had a raised 
level of CA125 of $339.20 \mathrm{IU} / \mathrm{ml}$ with significant ascites and large pleural effusion of $800 \mathrm{cc}$.

On Ultrasound the appearance of SSTs may be suspected to be malignant ovarian tumors because they show mixed pattern with cystic and solid components. ${ }^{6}$ In our case, on USG mass was proved to be solid \& cystic \& measured approximately $15 \mathrm{~cm} \times 14 \mathrm{~cm} \times 6 \mathrm{~cm}$. CT scan demonstrated large pelvic mass accompanied by ascites $\&$ right pleural effusion. Some studies have suggested that MRI findings may be more specific in distinguishing this benign neoplasm from other malignant ovarian tumors which include a large mass with hyperintense cystic components or heterogenous solid mass of intermediateto-high signal intensity on T2 weighted MRI and thus help in preoperative diagnosis, thereby preventing excessive surgical intervention.

\section{CONCLUSION}

Due to extremely low incidence of SST, it is not always easy to predict its presence preoperatively. Clinical and ultrasonographic findings may be suggestive of malignant neoplasm. In a young patient with solid ovarian mass, possibility of SST should be kept in mind. Frozen section can help in conserving the fertility.

\section{ACKNOWLEDGEMENT}

We are thankful to department of pathology of Smt Kashibai Navale medical college, Pune for providing histopathology pictures of the case.

\section{REFERENCES}

1. Iravanloo G1, Nozarian Z, Sarrafpour B, and Motahhary P. Sclerosing Stromal Tumor of the Ovary. Arch Iranian Med 2008; 11 (5): 561-562.

2. Liou JH, Su TC and Hsu JC. Meigs' syndrome with elevated serum cancer antigen 125 levels in a case of ovarian sclerosing stromal tumor. Taiwanese Journal of Obstetrics \& Gynecology 2011; 50:196-200.

3. Akbulut M, Colakoglu N, Soysal ME and Duzcan SE. Sclerosing stromal tumor of the ovary: Report of a case and review of the literature. Aegean Pathology Journal 2004; 1, 84-89.

4. de Silva' MVC and Amarasekera LR. Sclerosing stromal tumour of the ovary, a case report. The Ceylon lournal of Medical Science 1996; 39: 57-59.

5. Meigs $\mathrm{J}$ V. Fibroma of the ovary with ascites and hydrothorax; Meig s syndrome. Am J Obstet Gynecol 1954; 67 (5): 962-985.

6. Joja I, Okuno K, Tsunoda M, Yoshihiro T, Katsuhiko S, Yasushi $\mathrm{M}$, et al. Sclerosing stromal tumor of the ovary: US, MR, and dynamic MR findings, Journal of Computer Assisted Tomography 2001; 25(2): 201-206.

7. Ihara N, Togashi K, Todo G, Nakai A, Kojima N, Ishigaki T, et al. Sclerosing stromal tumor of the ovary: MRI. Journal of Computer Assisted Tomography, 1999: 23:555-557.

\section{Authors Contribution:}

JK - Operated the patient, prepared the manuscript; PT - Involved in surgery and patient management; PN - Supervised management, reviewed the manuscript.

Source of Support: Nil, Conflict of Interest: None declared. 